\title{
Bad Apples: \\ Political Paralysis and the Quality of Politicians
}

\author{
Gabriel J. Leon* \\ London School of Economics \\ August 2009
}

The Suntory Centre

Suntory and Toyota International Centres for

Economics and Related Disciplines

London School of Economics and Political Science Houghton Street

London WC2A 2AE

EOPP 13

Tel: (020) 79556674

\footnotetext{
* Address: STICERD, London School of Economics, Houghton Street, London WC2A 2AE, United Kingdom. Email: g.j.leon@lse.ac.uk. Website: http://personal.lse.ac.uk/leongj. Tel: +44 7952523004. I wish to thank Tim Besley, Christopher Bliss, Paul Klemperer, Clare Leaver, Gilat Levy, Sebastian Linnemayr and Meg Meyer for their help and comments. I kindly acknowledge the financial support of the ESRC.
} 


\begin{abstract}
Why do elected officials often suffer from political paralysis and fail to implement the best policies available? This paper considers a new yet intuitive explanation that focuses on the quality of the politicians competing to replace the incumbent. The key insight is that a 'good' incumbent with preferences identical to those of a representative voter will want to keep corrupt politicians out of office; she may do so by distorting her policy choices to signal her type and win re-election. The value of signalling and staying in office increases with the fraction of corrupt types in the population of politicians. Electing good types may therefore not be enough to ensure that the best policies are implemented, especially when corrupt politicians are common. This provides a new explanation for why political failure is particularly severe in corrupt democracies.
\end{abstract}

JEL Codes: H1, H54, D7, O10.

Keywords: political agency, corruption, elections, term limits, economic reform, politician quality. 
This series is published by the Economic Organisation and Public Policy Programme (EOPP) located within the Suntory and Toyota International Centres for Economics and Related Disciplines (STICERD) at the London School of Economics and Political Science. This new series is an amalgamation of the Development Economics Discussion Papers and the Political Economy and Public Policy Discussion Papers. The programme was established in October 1998 as a successor to the Development Economics Research Programme. The work of the programme is mainly in the fields of development economics, public economics and political economy. It is directed by Maitreesh Ghatak. Oriana Bandiera, Robin Burgess, and Andrea Prat serve as codirectors, and associated faculty consist of Timothy Besley, Jean-Paul Faguet, Henrik Kleven, Valentino Larcinese, Gerard Padro i Miquel, Torsten Persson, Nicholas Stern, and Daniel M. Sturm. Further details about the programme and its work can be viewed on our web site at http://sticerd.lse.ac.uk/research/eopp.

Our Discussion Paper series is available to download at:

http://sticerd.lse.ac.uk/_new/publications/series.asp?prog=EOPP

For any other information relating to this series please contact Leila Alberici on:

Telephone: UK+20 79556674

Fax: $\quad$ UK+20 $\quad$ : $\quad$ (a556951

Email: $\quad$ l.alberici @lse.ac.uk

(c) The author. All rights reserved. Short sections of text, not to exceed two paragraphs, may be quoted without explicit permission provided that full credit, including (C) notice, is given to the source. 


\section{Introduction}

An important question in public economics is why 'good' politicians often fail to implement the best policies available. For example, elected officials in many countries often avoid the economic reforms and public investment projects that would lead to greater economic growth. For instance, the World Bank reports that Latin American countries are spending less than $2 \%$ of their GDP on infrastructure, and that this low level of investment is hindering economic growth and poverty reduction (Fay and Morrison, 2005). The literature on political agency has shown that this failure can arise when the incumbent has a legacy motive and receives ego-rents from being in office, or when she receives utility only while in office (e.g. Maskin and Tirole, 2004). These explanations, however, rely on specific assumptions about the preferences of politicians; in particular, they assume politicians are never 'truly good'.

In this paper we show that the best policies may be avoided even by politicians who are truly good, in the sense that their preferences are identical to those of voters. The mechanism behind this political failure is new to the literature, although it is very intuitive. A good politician derives utility even when she is out of office, and values a good policy regardless of whether it was implemented by her or by somebody else. ${ }^{1}$ When some of the other politicians are corrupt, she will want to keep them out of office and avoid the policies they would implement. One way of doing this is by staying in office herself. This is our key insight: part of the value of being in office lies in keeping corrupt politicians out of power, and this value increases with the fraction of corrupt types in the population of politicians. The composition of the political class therefore matters, and in countries where most politicians are corrupt we would expect this political failure to be particularly severe.

We work with a political agency model with two types of politicians: bad politicians who are corrupt, and good politicians who have preferences identical to those of voters. In each period an incumbent, who is good or bad, must choose whether to implement a policy or not (i.e. become paralyzed). If she chooses to implement a policy, it can be of two types: a long-term or a rent-extraction policy. Long-term policies require an investment today and provide a return after the next election. Rent-extraction policies allow the incumbent to appropriate funds, but produce no return. ${ }^{2}$ Both policies look identical in the period they are implemented; their type becomes obvious once their re-

\footnotetext{
${ }^{1}$ That is, she solves an infinite horizon problem that takes into account the policies implemented in all future periods.

${ }^{2}$ Our results will hold even when rent-extraction provides some public return, as long as it is lower than that of long-term policies.
} 
turn materializes (or not). This is an accurate description of many policies; for example, public investment projects. Public projects can be used by corrupt politicians to extract rents, and whether this is the case is not immediately clear because the returns do not materialize for years. For example, it might take years before a dam is finished and it is announced that it will operate at a fraction of its capacity. Even when there is no substantial delay in the realization of the returns, a corrupt incumbent might succeed in hiding the true outcome of his policies by, for example, manipulating government statistics or limiting the amount of information the press can report. ${ }^{3}$

Naturally, corrupt politicians will want to implement the rent-extraction policies. In order to differentiate herself from them, a good incumbent may choose to signal her type by becoming paralyzed, doing nothing instead of implementing a long-term policy. Since this is costly, she will do so only when the value of ensuring that future politicians are good is high; in other words, when a large fraction of politicians is corrupt. As a result, choosing a good politician does not ensure that the best policies will be implemented, as the quality of her challengers matters too.

The model yields three main insights. First, paralysis may arise in equilibrium when the proportion of corrupt politicians is high; this provides a new explanation for why political failure is particularly severe in corrupt democracies. In this equilibrium paralysis in the first period allows the good incumbents to signal their type and win re-election. Although costly because it involves not implementing a long-term policy in the first period, paralysis allows the good politician to delay the election of a future incumbent who might be corrupt. Therefore, paralysis is only valuable when it is likely that the successors will be corrupt, which is the case when the proportion of bad politicians is high. This suggests that we need to look beyond elections at how citizens decide to enter politics. Along these lines, we show that allowing for endogenous entry into politics has no clear effect on paralysis: paralysis may keep corrupt citizens from entering politics and this makes it more attractive; but this lack of entry improves the average quality of politicians, decreases the value of re-election, and makes signalling through paralysis less attractive.

Second, longer term limits decrease the proportion of bad politicians for which the good types become paralyzed, and thus makes it more likely. This is because in equilibrium paralysis in the first term reveals the good politician's type, independently of the term limit. The benefit of retaining the good incumbent, however, increases with the

\footnotetext{
${ }^{3}$ This was the strategy followed by Alberto Fujimori in Peru; McMillan and Zoido (2004) provide a fascinating analysis of this case. For the role of the media in constraining the behavior of politicians, see Besley and Prat (2006).
} 
number of terms that she is allowed to remain in office. The fact that the election of a possibly corrupt successor is delayed further into the future translates into paralysis being optimal even when the fraction of bad politicians is small.

Third, although paralysis may be eliminated by reducing term limits, this is not optimal when the proportion of bad politicians is high. This is because paralysis allows for what the political agency literature calls 'selection': voters identify bad incumbents and vote them out of office. ${ }^{4}$ Paralysis can be optimal precisely because it allows voters to distinguish between the good and bad types, so that they can re-elect the good and remove the bad. Selection is particularly valuable when most politicians are bad, so that you wish to identify those rare good types and keep them in office, and remove the bad straight away. When most politicians are good, on the other hand, selection is not very useful and it is optimal to avoid paralysis. This causes the bad types to be re-elected too often, but this is not a major concern since bad politicians are rare. It also causes good types to be voted out too often, but since the successor is likely to be good, this is not very costly.

Paralysis is similar to 'pandering', a term used by Maskin and Tirole (2004) to describe instances in which re-election concerns lead a politician to choose an inferior but popular action. Pandering arises because politicians are motivated by the benefits they can enjoy only when in office: being the one who implements the good policies (the legacy motive) and the enjoyment of power for its sake alone (ego-rents). Smart and Sturm (2006) refer to pandering as a reason for having two term limits. In their model, politicians value being in office and may implement suboptimal policies in order to win re-election. Term limits shorten their horizon and hence lower the value of re-election, leading to "truthful behavior" as each incumbent type implements her preferred policy.

Our paper differs in two main respects. First, we consider politicians who receive utility even when out of office, and show that a distortion can arise for a different reason: good politicians wish to keep potentially corrupt future incumbents out of office for as long as possible. Second, we emphasize the negative impact the presence of corrupt politicians has on the behavior of good incumbents. We show that paralysis and long term limits may be optimal when the proportion of bad politicians is high. Our results suggest that countries with high levels of corruption, like many in the developing world, are more likely to suffer from paralysis. This provides one explanation for why these countries often fail to implement economic reform programs and development policies that would clearly have a positive impact on their economies. ${ }^{5}$

\footnotetext{
${ }^{4}$ See Besley (2005), Besley (2006) and Besley and Smart (2007).

${ }^{5}$ There is also an important modelling difference in that our good politicians solve an infinite period
} 
Our concern with the identity of future policymakers is also a key feature in Tabellini and Alesina (1990), where budget deficits may arise because a current majority wishes to tie the hands of a future majority with potentially different policy preferences. As in our paper, policies are chosen primarily because they reduce the future government's ability to implement policy; in Tabellini and Alesina (1990) it is by tying up resources, while here it is by keeping other politician types out of office. The equilibria in this paper are similar to those in Rogoff (1990), who focuses on competency as an explanation for the political budget cycle. In his model, politicians distort their policy choices in order to signal their innate abilities to voters. The failure of good politicians to implement long-term policies is also related to the concept of policy myopia studied by Aidt and Dutta (2007). Finally, our analysis has placed particular emphasis on the impact corrupt politicians have on the actions of the good types. Understanding how citizens decide to enter politics, and whether they will be good or bad politicians, is a very important question that has been partly addressed by Besley (2005) and Caselli and Morelli (2002).

This paper is also closely related to the literature on the implementation of economic reform. A well-known paper by Fernandez and Rodrik (1991) focuses on how ex-ante uncertainty about the distribution of the gains from reform can cause a majority to oppose a policy, even though ex-post a (potentially different) majority would support it. Alesina and Drazen (1991) look at why macroeconomic stabilization is often delayed. They argue that stabilizations involve a cost, and that conflict about how this cost is distributed between different groups in society leads to a war of attrition that delays the stabilization. Our paper addresses a similar question, but focuses on a different explanation that is based on political agency.

The rest of this paper is organized as follows: Section 2 presents the model. Section 3 derives the main result of the model and considers some generalizations and extensions. Section 4 provides some concluding remarks and suggests some avenues for future research.

\section{$2 \quad$ A Model of Policy Implementation}

In this section we develop a political agency model that follows the pioneering work of Barro (1973) and Ferejohn (1986), ${ }^{6}$ where an incumbent politician must choose a single policy in every period that she is in office. She can run for re-election but can only be in problem. In Maskin and Tirole (2004) and Smart and Sturm (2006) politicians do not value the future after they leave office.

${ }^{6}$ There is also a parallel empirical literature that finds evidence in support of the predictions of these models; for example, Besley and Case (1995a,b, 2003) and List and Sturm (2006). 
office for at most $T$ periods, after which a new politician must be elected, i.e. she faces a $T$ term limit. Voters are infinitely lived and at the end of each period must choose whether to re-elect the incumbent or vote for a challenger who is randomly drawn from the pool of politicians.

Politicians can be of two types: good or bad. Good politicians have preferences identical to those of voters; they value all payoffs to the voters and nothing else. In particular, they value these payoffs regardless of whether they themselves are in office, which implies that their preferences are over an infinite horizon. Their utility is given by

$$
V_{t}^{G}=\sum_{j=t}^{\infty} v_{j}^{G}
$$

where $v_{j}^{G}$ is the per period payoff. Bad politicians, on the other hand, only value any rents they may extract while in office. Their utility is given by

$$
V_{t}^{B}=\sum_{j=t}^{\infty} v_{j}^{B} \times I_{j}
$$

where $I_{j}=1$ if the bad politician is the incumbent in period $j$, and $I_{j}=0$ otherwise. A proportion $\pi$ of politicians is good.

Voters' utility is also given by $V_{t}^{G}$. They receive a fixed income $y$ each period and cannot directly observe whether a politician is good or bad, although they know that a proportion $\pi$ is good. They will re-elect the incumbent, provided she has been in office for less than $T$ periods, with a probability $\sigma$ that maximizes the expected present discounted value of their stream of future payoffs. All players share a discount factor of $\delta$.

The politicians must choose whether to implement a policy $(\mathrm{P})$ or do nothing $(\mathrm{N})$. The cost of implementing a policy is $\phi y$, and the policy can be of two types: a longterm policy (L) or a rent-extraction policy $(\mathrm{X})$. Long-term policies generate $\phi y(1+r)$ at the beginning of the following period. For simplicity, we assume that this cannot be expropriated or re-invested, and it all accrues to the voters. Rent extraction policies allow politicians to expropriate the amount $\phi y$ in the current period and generate no return in the next. One can think of this in terms of one policy $(\mathrm{P})$ that can be implemented in one of two possible ways, $(\mathrm{L})$ or $(\mathrm{X})$ : for example, an infrastructure project may be built properly or the money may be stolen and the project left unfinished. ${ }^{7}$ At the time

\footnotetext{
${ }^{7}$ Our differentiation between the two types of policies aims for simplicity and is admittedly stark, as in practice one would expect most policies that allow for rent extraction to also generate some social benefit.
} 
of implementation, voters can only see that something is being done $(\mathrm{P})$, but cannot distinguish between (L) and (X). Only at the beginning of the next period when the return materializes (or not) do voters discover the type of policy that was adopted.

Except for the politician's type and whether the policy implemented was a long-term or a rent-extraction policy, everything is public information. The total payoffs received by a good politician and the voters in period $t$ depend on the policy implemented:

$$
v_{t}^{G}=\left\{\begin{array}{ccc}
y & \text { if } & \text { policy }=N \\
(1-\phi) y+\delta \phi y(1+r) & \text { if } & \text { policy }=L \\
(1-\phi) y & \text { if } & \text { policy }=X
\end{array}\right\}
$$

where we assume that long-term policies (L) have a positive net present discounted value, i.e. $\delta(1+r)>1$. We will say that a good incumbent suffers from political paralysis when he fails to implement a long-term policy (L). Similarly, the total payoffs for a bad politician from period $t$ policies are

$$
v_{t}^{B}=\left\{\begin{array}{ccc}
0 & \text { if } & \text { policy }=N \\
0 & \text { if } & \text { policy }=L \\
\phi y & \text { if } & \text { policy }=X
\end{array}\right\}
$$

This setup incorporates a number of important assumptions. First, good types value policy outcomes that occur even after they have left office, while bad incumbents do not. We feel this is realistic since one would expect good politicians to consider the future consequences of their decisions in a way that bad politicians would not. Second, we assume that a policy's outcome is not observable until the next period. This is true of numerous policies, e.g. those associated with growth and development, education, a fiscal stimulus, etc. ${ }^{8}$ Finally, we have assumed that rent-extraction must take place through rent-extraction policies and that direct looting is not possible. ${ }^{9}$

Let $1 \leq t \leq T$ refer to the current incumbent's $t^{t h}$ term in office. The voters' beliefs about the incumbent's type depend on the policies she implements and whether there has been a change in the incumbent's identity. Their ex-ante belief, formed after the returns from the previous period's policy have been realized but before the current period's policy has been chosen, is denoted by $\mu_{t}^{a}$ where

$$
\mu_{t}^{a}=\operatorname{Pr}(\text { incumbent is good } \mid \text { information at beginning of period } t)
$$

\footnotetext{
${ }^{8}$ We are also assuming that citizens cannot directly observe a politician's type. This assumption is common in the literature; see, for example, Coate and Morris (1995) and Besley (2006).

${ }^{9}$ Coate and Morris (1995) show why incumbents may choose indirect rent-extraction methods.
} 
where $\mu_{t}^{a}=\pi$ if a new incumbent has been voted into office; otherwise it is given by $\mu_{t}^{a}\left(\rho_{t-1}, \mu_{t-1}^{p}\right)$, where $\rho_{t-1}$ is the policy implemented in period $t-1$, where $\rho_{t-1} \in$ $\{N, L, X\}$. Any new information is incorporated using Bayes' rule.

This is updated into the ex-post belief $\mu_{t}^{p}$ after the period $t$ policy is implemented:

$$
\mu_{t}^{p}=\operatorname{Pr}\left(\text { incumbent is good } \mid \rho_{t}^{\prime}, \mu_{t}^{a}\right) .
$$

where $\rho_{t}^{\prime} \in\{N, P\}$ is the policy type implemented in period $t$ and Bayes' rule is used to incorporate any new information. The voters re-elect the incumbent with probability $\sigma_{t}\left(\mu_{t}^{p}\right)$, where $\sigma_{t}: \mu_{t}^{p} \rightarrow[0,1]$ and is chosen to maximize their expected payoff.

We can now describe the timeline of the game in each period $t$ :

(1) i) If $t=1$, nature chooses an incumbent who is good with probability $\pi$ and $\mu_{t}^{a}=\pi$. ii) If $t>1$ and a policy $(P)$ was implemented in the previous period, it is revealed to have been $(L)$ or $(X)$, and the voters form $\mu_{t}^{a}$ using Bayes' rule. iii) Otherwise $\mu_{t}^{a}=\mu_{t-1}^{p}$.

(2) The incumbent decides whether to implement a policy $(P)$ or not $(N)$. If she implements a policy, then she must decide whether it is a long-term $(L)$ or a rent-extraction $(X)$ policy.

(3) The voters observe whether a policy was implemented or not $\{N, P\}$, and form their ex-post belief $\mu_{t}^{p}$ using Bayes' rule.

(4) i) If $t<T$, the voters re-elect with probability $\sigma_{t}\left(\mu_{t}^{p}\right)$. If re-election occurs, $t$ increases by 1 . ii) If not, or if $t=T$, then set $t=1$.

The payoffs in this game depend entirely on the incumbent's type and the voters' beliefs about the incumbent's type, as given by $\mu_{t}^{a}$ and $\mu_{t}^{p} \cdot{ }^{10}$ It then seems natural to focus on the Markov Perfect equilibria of the game, so that strategies can only be contingent on payoff relevant state variables and the history of the actions taken in period $t$. This rules out any effects due to the past interaction between voters and previous governments, not an unreasonable restriction considering that the identity of the incumbent has changed.

Define the mappings $\alpha_{t}^{g}: \mu_{t}^{a} \rightarrow\{N, L, X\}, \alpha_{t}^{b}: \mu_{t}^{a} \rightarrow\{N, L, X\}$ and $\sigma_{t}: \mu_{t}^{p} \rightarrow[0,1]$. Here $\alpha_{t}^{g}\left(\mu_{t}^{a}\right)$ is the policy implemented by a good incumbent in period $t$ if the voters'

\footnotetext{
${ }^{10}$ Whether a long-term policy was implemented in the last period of the previous government will also affect payoffs, but since we have assumed these payoffs cannot be expropriated or reinvested and utility is linear, they have no influence on the strategies chosen.
} 
ex-ante belief is $\mu_{t}^{a}$, and similarly with $\alpha_{t}^{b}$ for the bad type. For the voters, $\sigma_{t}\left(\mu_{t}^{p}\right)$ is the probability that they re-elect an incumbent they believe to be good with probability $\mu_{t}^{p}$. A strategy for a good incumbent is $S^{G}=\left\{\alpha_{1}^{g}, \ldots, \alpha_{T}^{g}\right\}$, for a bad incumbent is $S^{B}=$ $\left\{\alpha_{1}^{b}, \ldots, \alpha_{T}^{b}\right\}$ and for the voters $S^{V}=\left\{\sigma_{1}, \ldots, \sigma_{T-1}\right\}$. A strategy profile $\left(S^{G}, S^{B}, S^{V}\right)$ and the set of beliefs $\left(\mu_{1}^{a}, \mu_{1}^{p}\right) \times \ldots \times\left(\mu_{T}^{a}, \mu_{T}^{p}\right)$ are a MPE if after any within period history, each player's strategy is optimal given every other player's strategy and beliefs, where beliefs are computed from the equilibrium strategies using Bayes' rule.

\section{Political Paralysis}

We first focus on the case where incumbents face a two term limit; it provides most of the insight without the difficulties that higher term limits introduce (which we consider in Section 3.3).

\subsection{Two Term Limit}

We restrict our attention to instances where paralysis arises as part of an equilibrium in which politicians have pure strategies. Solving backwards, in period 2 the good types always implement a long-term policy (L) and the bad types always extract rents (X). We should note that this is also the solution to the one term limit case, where incumbents are not allowed to be re-elected.

In the first period the bad types also always extract rents, since doing so ensures them a payoff of at least $\phi y$, while implementing $(\mathrm{L})$ or $(\mathrm{N})$ provides a payoff of at most $\delta \phi y$, and only if they win re-election after the first period. In short, rent extraction strictly dominates the other policy choices for the bad types. The good types will then optimally choose between $(\mathrm{N})$ and $(\mathrm{L})$. There is only one (pure strategy) equilibrium with paralysis and it involves strategies $S^{G}=(N, L)$ and $S^{B}=(X, X)$ for the politicians. We will refer to this as the paralysis equilibrium.

We assume that this profile represents part of an equilibrium and derive the conditions that must hold for this to be the case. The choice of policy in period 1 will completely reveal the incumbent's type, ${ }^{11}$ and the optimal voting rule calls for $\sigma_{1}(1)=1$ and $\sigma_{1}(0)=0$, since the incumbent can do no better than re-elect a good type (since he chooses policy (L)) and no worse than re-elect a bad type (since he always extracts rents). This equilibrium calls for a good incumbent to be paralyzed in the first period, be re-elected with probability 1 , and then implement a long-term policy in the second

\footnotetext{
${ }^{11}$ Formally, $\mu_{1}^{p}(N, \pi)=1$ and $\mu_{1}^{p}(P, \pi)=0$.
} 
period. The bad types always extract rents in the first period and are voted out of office. If the good incumbent deviates and implements (L), he is voted out of office.

Given this voting rule, we need to derive the condition for the good types not to deviate. We do so by finding when $V^{G}(N)>V^{G}(L)$, where these are the payoffs to the good incumbent from implementing no policy and from implementing a long-term policy in the first period, respectively. We can write

$$
V^{G}(N)=[y+\delta[(1-\phi) y+\delta \phi y(1+r)]]+\delta^{2} K
$$

where the term in brackets is the payoff from no policy in period 1, which leads to certain re-election and a long-term policy in period 2. After this, the term limit binds and a new incumbent must be elected, with the continuation payoff given by $K$. Similarly, we can write

$$
V^{G}(L)=[(1-\phi) y+\delta \phi y(1+r)]+\delta K
$$

where now the first term in brackets reflects the payoff from a period 1 deviation to policy (L), which causes a certain loss of the election and an earlier arrival of the continuation payoff $K$.

In order to establish the value of $K$, we observe that the Markov restriction implies that if the paralysis equilibrium strategies are followed by the current incumbent, they will be followed by all future incumbents. This implies the recursive relation $K=$ $\pi\left[y+\delta[(1-\phi) y+\delta \phi y(1+r)]+\delta^{2} K\right]+(1-\pi)[(1-\phi) y+\delta K]$, where we have taken into account the fact that the new incumbent will be good with probability $\pi$. We solve for $K$ to obtain

$$
K=\frac{[y-(1-\pi) \phi y]+\pi \delta[(1-\phi) y+\delta \phi y(1+r)]}{1-\left(\pi \delta^{2}+(1-\pi) \delta\right)}
$$

This is the formula for an infinite geometric series, where the numerator is the expected payoff to voters from period $t$ policies under the paralysis equilibrium, and the denominator is 1 minus the weighted discount factor. The first term in the numerator, $y-(1-\pi) \phi y$, is the expected period 1 payoff, given that in equilibrium a good incumbent implements $(\mathrm{N})$ and a bad type chooses $(\mathrm{X})$. The second term, $\pi \delta[(1-\phi) y+\delta \phi y(1+r)]$, is $\pi$ times the discounted payoff from having a good politician in office in period 2. There is no period two counterpart for the bad types because they are voted out of office at the end of period 1 . The weighted discount factor $\pi \delta^{2}+(1-\pi) \delta$ reflects that the good types stay in office for two periods, so that " $\pi$ of the time" we must discount by $\delta^{2}$, while the bad types stay only for one period, so that " $1-\pi$ of the 
time" we must only discount by $\delta$.

Comparing (1) and (2) and using (3) we find that $V^{G}(N)>V^{G}(L)$ when

$$
\pi<1-\frac{\delta(1+r)-1}{\delta^{2}(1+r)} \equiv \widehat{\pi}_{2}
$$

This establishes the following result:

Proposition 1 With a two term limit, political paralysis is an equilibrium when the proportion of good types in the pool of politicians is sufficiently low, as defined by $\pi<\widehat{\pi}_{2}$.

In this two period case the good incumbent faces a decision between implementing the policy today and being voted out of office, and waiting one period doing nothing and implementing the policy in the next. The net cost of delaying the implementation of $(\mathrm{L})$ is given by

$$
V^{G}(N)-V^{G}(L)=y-(1-\delta)[(1-\phi) y+\delta \phi y(1+r)+\delta K]
$$

Delay is optimal when this cost is small, which is the case only if the value of $K$ is small enough. This, in turn, requires that $\mathrm{K}$ be composed of many instances where $(\mathrm{X})$ is implemented, which will be the case if a large proportion of politicians is bad. In this case a good incumbent will try to delay the potential election of a bad politician, even if that requires that he alter his own policy choices. When there are few bad politicians, however, this strategy is too costly: the incumbent might as well implement a longterm policy, since after losing the election he is bound to be followed by another good politician.

It is straightforward to verify that the value $\widehat{\pi}_{2}$ is decreasing in $r$. This is because a higher return makes long-term policies more productive, and thus increases the net cost of delay. In particular, this causes $K$ to increase, and so the proportion of bad politicians $1-\pi$ necessary to make paralysis optimal will increase.

Alternatively, we can solve for $r$ in (4):

$$
r<\frac{1}{\delta[1-\delta(1-\pi)]}-1 \equiv \widehat{r}_{2}
$$

where now $\widehat{r}_{2}$ gives us the maximum rate of return for which paralysis will be optimal. When the returns are above this level, delay is too costly and the good incumbent will implement the long-term policy. An increase in $\pi$ decreases $\widehat{r}_{2}$ : when the proportion of good politicians is high, the return from policies needs to be low for paralysis to be 
optimal. This has the implication that when most politicians are bad (i.e. $\pi$ is low), only policies with very high rates of return will be implemented.

We should note that there is also a family of equilibria in which the good types implement (L). We will denote its representative member the "no paralysis equilibrium", since it involves the good types playing (L) and the bad types playing (X) in both periods, and both getting re-elected with at least some minimum probability $\sigma \geq \underline{\sigma}(\pi, \delta, r)$. To compute the value of $\underline{\sigma}$, note that in this equilibrium the good incumbent receives

$$
V^{G}(L)=(1-\phi) y+\delta \phi y(1+r)+\sigma \delta[(1-\phi) y+\delta \phi y(1+r)+\delta K]+(1-\sigma) \delta K
$$

because she implements a long-term policy in the current period; if re-elected, she implements another long-term policy and must leave office, if not re-elected, she leaves office and a new incumbent takes over. If she deviates, her payoff is given by

$$
V^{G}(N)=y+\delta[(1-\phi) y+\delta \phi y(1+r)+\delta K]
$$

because she is found to be good after doing nothing in the first period, and so is re-elected and implements a long-term policy in the next period. In equilibrium, the continuation value is one where the good always implement long-term policies and the bad always extract rents, and so is given by

$$
\begin{aligned}
K & =\pi[(1-\phi) y+\delta \phi y(1+r)+\delta \sigma[(1-\phi) y+\delta \phi y(1+r)+\delta K]+\delta(1-\sigma) K] \\
& +(1-\pi)[(1-\phi) y+\delta \sigma[(1-\phi) y+\delta K]+\delta(1-\sigma) K]
\end{aligned}
$$

which gives the value of $K$ :

$$
K=\frac{(1-\phi) y+\pi \delta \phi y(1+r)+\delta \sigma(1-\phi) y+\pi \delta^{2} \sigma \phi y(1+r)}{1-\delta^{2} \sigma-\delta(1-\sigma)}
$$

The no deviation condition is given by $V^{G}(L)>V^{G}(N)$, and solving using the above expressions gives the condition:

$$
\sigma>\underline{\sigma} \equiv \max \left[0, \frac{1-\delta(1+r)[1-\delta(1-\pi)]}{\delta^{2}(1+r)(1-\pi)}\right]
$$

where $\underline{\sigma}$ is decreasing in $\pi$. The voters are indifferent between the values of $\sigma$, because in equilibrium the ex-post probability of a good type in period 1 is still $\pi$ (because of the pooling). Re-electing the incumbent or choosing a new randomly drawn politician results in the same continuation value. 


\subsection{Endogenous Politician Quality}

In this section we allow citizens to determine whether to participate in politics, so that the quality of the pool of politicians becomes endogenous. A valid question to ask in this context is whether it becomes easier to support a paralysis equilibrium. We show that endogenizing politician quality can have an ambiguous effect.

Suppose that there are $N$ citizens, and a proportion $\pi$ of them is good. Denote by $\pi^{e}$ the proportion of politicians who are good. Furthermore, let us suppose that entry is costless for the good types, since they are public-spirited, but the bad types face a cost $\rho>0$ per election. Let $e$ be the fraction of bad citizens who enter politics.

It follows that all good citizens become politicians, and that bad types will enter as long as

$$
\rho<\frac{1}{\pi N+e(1-\pi) N} \phi y
$$

where $\phi y$ are the per-period rents they extract, and $\frac{1}{\pi N+e(1-\pi) N}$ is the probability that they are elected. Solving for $e$ we find that ${ }^{12}$

$$
e=\left\lceil\frac{\phi y}{\rho(1-\pi) N}-\frac{\pi}{1-\pi}\right\rceil
$$

where $\lceil$.$\rceil denotes rounding down to the closest integer. Note that the condition e \leq 1$ implies that $\frac{\phi y}{\rho N} \leq 1$. We can then write

$$
\pi^{e}=\pi \frac{\rho N}{\phi y}
$$

so that the proportion of good politicians is now higher because some bad citizens may not enter politics.

Will paralysis be supported for a greater range of $\pi$ values? The answer is unclear: on the one hand, paralysis reduces entry of bad citizens, and so one would expect it to arise for a greater range of $\pi$ parameter values. On the other hand, this effect reduces the cost of being voted out of office, since the incumbent is more likely to be followed by another good politician. So it is unclear whether deviations from the paralysis equilibrium by the good incumbent become optimal for a greater range of $\pi$ values.

\footnotetext{
${ }^{12} \mathrm{We}$ are assuming that the solution is positive.
} 


\subsection{General Case: $\mathbf{T}>2$ Term Limit}

Allowing for longer term limits does not affect the analysis in any fundamental way, although it poses a number of additional technical difficulties. In particular, it is no longer strictly dominant for the bad types to extract rents. This is easy to see in the case of three terms: the bad types might find it optimal to pool in the first period if that allows them to win re-election with positive probability and extract rents in the latter two periods. This in turn implies that we can no longer limit the good types' decision to one between $(\mathrm{N})$ and $(\mathrm{L})$. It might be possible, for example, for both types to pool on $(\mathrm{X})$. This type of behavior on the part of the good types seems counter-intuitive, so for simplicity we make the following assumption:

Assumption Good politicians never extract rents (X).

We leave the derivation of the equilibria to the Appendix, but as before, the only equilibrium with paralysis involves the good type being paralyzed in the first period, being recognized as good and then re-elected until term limits bind, while implementing (L) in every remaining period. Meanwhile, the bad types implement $(\mathrm{X})$ in the first period and are voted out of office. Bad types will not deviate if the gain from extracting rents in period 1 and being voted out of office, $\phi y$, exceeds the equilibrium gain from deviation, $\delta[\phi y+\delta \phi y]$. This latter expression reflects the fact that pooling in period 1 allows the bad type to win re-election, extract rents in period 2 , be taken for a good incumbent and win re-election for a third period; he then extracts rents in periods 2 and 3. Solving for the above conditions shows that the bad incumbent will not deviate if $\delta^{2}+\delta \leq 1$. $^{13}$

As in the previous section, the good type will not deviate if

$$
\pi<1-\frac{(1-\delta)}{\left(1-\delta^{T-1}\right)} \frac{\delta(1+r)-1}{\delta^{2}(1+r)} \equiv \widehat{\pi}_{T}
$$

We can then state the following results:

Proposition 2 (i) With a term limit of $T$, political paralysis may arise in equilibrium when the proportion of good types in the pool of politicians is sufficiently low, as defined by $\pi<\widehat{\pi}_{T}$, and politicians are sufficiently impatient, as given by $\delta^{2}+\delta \leq 1$. (ii) Longer term limits lead to the possibility of paralysis at increasingly higher value of $\pi$, since $\widehat{\pi}_{T-1}<\widehat{\pi}_{T}$ for all $T$.

\footnotetext{
${ }^{13}$ We can write this as $\delta \leq 0.62$, which is the solution for $\delta^{2}+\delta \leq 1$ that falls in $[0,1]$.
} 
When politicians are impatient, the bad types will always extract rents in the first period $(\mathrm{X})$ and be voted out of office. On the other hand, good types will be paralyzed in the first period, convey their type to voters, and win re-election until term limits bind. They implement long-term policies in every period except the first.

As term limits increase, political paralysis can arise for a smaller proportion of bad politicians. This is because the longer the term limit, the more valuable it is to identify good types, since you can keep them longer. The cost of identification, on the other hand, is the same in all cases: paralysis in the first period. Being able to keep the good politicians longer allows them to implement long-term policies in all but the first period, and make paralysis more attractive.

As before, there is also a family of equilibria in which the good types implement (L) and the bad types implement $(\mathrm{X})$ in every period. In period 2 the voter sees whether the period 1 policy was $(\mathrm{L})$ or $(\mathrm{X})$, and re-elects until the term limit binds if it was a long-term policy, and votes the incumbent out of office if it was a rent-extraction scheme.

Finally, note that there is no paralysis when no re-election is allowed. We have argued that paralysis arises because it allows good types to convey their type before an election. It is then natural that without re-election there should be no paralysis.

\subsection{Optimal Term Limits}

In the previous two sections we derived the conditions under which paralysis may arise as a function of the term limit $T .{ }^{14}$ One could then think of eliminating paralysis by simply reducing term limits; we have seen that there is no paralysis when term limits are set equal to one. This may not be optimal, however: paralysis allows voters to distinguish between the good and bad types, so that they can re-elect the good and vote the bad out of office. The fact that bad types can be identified and removed from office is referred to as 'selection' in the literature ${ }^{15}$.

In this section we show that paralysis may be optimal for voters. For simplicity, we restrict our attention to cases where $\delta^{2}+\delta \leq 1$; when other equilibria are possible, we assume paralysis is the one that arises. We can write the welfare for the one term limit

\footnotetext{
${ }^{14}$ There is a large literature that looks at the question of term limits. Aside from Smart and Sturm (2006), other interesting papers include Adams and Kenny (1986), Dick and Lott Jr. (1993), Glaeser (1997), and Lopez (2003).

${ }^{15}$ More generally, Besley (2005), Besley (2006) and Besley and Smart (2007) show that elections can serve to discipline and select bad politicians. Discipline refers to cases where the bad types constrain their behavior in order to remain in office. In our model, the bad types are never disciplined in equilibrium, because their type is revealed one period after they extract rents. Being disciplined then accomplishes nothing for them: it just delays the rents they could have extracted earlier.
} 
case as

$$
W_{1}=\frac{(1-\phi) y+\pi \delta \phi y(1+r)}{1-\delta} .
$$

Here the good implement $L$ and the bad choose $X$ every period. Because a new incumbent is elected every period, the welfare is simply a discounted sum of expected payoffs, where the expectation is with respect to the proportion of good types in the population.

For $T \geq 2$, the welfare generated by the paralysis equilibrium increases with $T$. The reason is intuitive: longer term limits do not increase the cost of paralysis, since it is always enough for the good incumbent to be paralyzed in the first period. Its benefits, on the other hand, increase as the good incumbents are allowed to stay in office longer, while bad politicians are voted out of office after period 1 . For $T \rightarrow \infty$, the welfare is given by

$$
W_{\infty}=\frac{\pi\left[y+\frac{\delta}{1-\delta}[(1-\phi) y+\delta \phi y(1+r)]\right]+(1-\pi)(1-\phi) y}{1-(1-\pi) \delta} .
$$

Once a good incumbent is voted into office, he is paralyzed in the first period but is then re-elected forever, implementing (L) in every period except the first. This is captured by the first term in the numerator. Bad types stay in office for only one period, and this is captured by the second term in the numerator. The denominator shows that incumbent changes are due only to the bad types being voted out of office.

The analysis requires that we consider the trade-off between changing incumbents every period, with a cost of voting good types out of office on occasion, and keeping the good ones when found, with the cost of paralysis in the first period. In general, one would expect the paralysis equilibrium to be optimal when the bad types are numerous: voters would want to identify the occasional good type and re-elect him, while voting the bad types out of office after one period. When most politicians are good, on the other hand, paralysis is costly and achieves little. In this case it is better to sometimes vote a good incumbent out of office, since it is likely that his successor will be a good politician too.

Comparing $W_{1}$ and $W_{\infty}$ gives us a sense for when paralysis may be optimal. Defining

$$
\widehat{\pi}_{w} \equiv \frac{1-\delta+\delta(1+r)(2 \delta-1)}{\delta^{2}(1+r)}
$$

we can state the following result:

Proposition 3 It can be optimal to induce political paralysis by not setting any term 
limits when the proportion of good politicians in the population is low, as given by $\pi<\widehat{\pi}_{w}$, and politicians are impatient, as given by $\delta^{2}+\delta \leq 1$.

In these cases it is valuable to identify those rare good politicians when they are in office, and then keep them in office forever. On the other hand, if $\pi$ is high, it is better to have the good types implement long-term policies in the first period. They get voted out of office, but since good politicians are abundant, it is likely that their successors will be good as well. To induce this behavior, term limits must be short.

\section{Concluding Remarks}

This paper has shown that the presence of corrupt politicians can induce public-spirited incumbents to become paralyzed. Paralysis allows the good types to communicate their type and win re-election, which is valuable because by staying in power they can delay the election of potentially corrupt successors. Paralysis becomes more likely as the proportion of bad types in the population increases.

Naturally, this explanation does not apply to every instance of political paralysis seen in practice. Since our argument relies on future elections inducing good types to become paralyzed, we cannot explain any instances where re-election is not allowed. In our model this limitation is underscored by the fact that good politicians never suffer from paralysis in their last period in office.

We have assumed throughout that the electoral system functions properly, in the sense that elections are fair and the outcomes are respected by all parties involved. The incumbent's only advantage comes from his ability to potentially convey information about his type through his choice of policy. In practice, in many regions of the world incumbents have a substantial number of advantages when running for re-election. In particular, we might expect the bad politicians to derive some (possibly illegal) incumbency advantages that increase their probability of winning re-election; for example, they could use the rents extracted while in office for campaigning. Our analysis relies on the implicit assumption that even when many politicians are corrupt, the electoral system will work properly. If this is not the case, then a one term limit might be optimal, as it might serve as a constitutional constraint. ${ }^{16}$

\footnotetext{
${ }^{16}$ For a model along these lines, see Glaeser (1997). However, even constitutional term limits have their limitations, as powerful leaders might pressure Congress into changing them. Latin America alone provides numerous recent examples: Menem in Argentina, Alvaro Uribe in Colombia, Alberto Fujimori in Peru, and Hugo Chavez in Venezuela.
} 
A number of avenues for future research should be mentioned. First, electoral systems not only differ in the number of times an incumbent is allowed to run for re-election, but also on how many years each period lasts. The length of each period would have implications for whether the outcome of a long-term policy is realized before or after the next election. A more flexible framework that allows us to vary both term limits and the length of each term would possibly provide additional insights. In addition, we have largely assumed the proportion of bad politicians to be exogenous to the electoral process. In reality, we would expect term limits, among other factors, to determine who runs for office. One could then hope to reduce the number of bad politicians by designing the electoral process appropriately. 


\section{References}

[1] Adams, James and Lawrence Kenny (1986), "Optimal Tenure of Elected Public Officials," Journal of Law and Economics 29, 303-328.

[2] Aidt, Toke and Jayasri Dutta (2007), "Policy Myopia and Economic Growth," European Journal of Political Economy 23, 734-753.

[3] Alesina, Alberto and Allan Drazen (1991), "Why are Stabilizations Delayed?," American Economic Review 81, 1170-88.

[4] Barro, Robert (1973), "The Control of Politicians: An Economic Model," Public Choice 14, 19-42.

[5] Besley, Timothy (2005), "Political Selection," Journal of Economic Perspectives 19, $43-60$.

[6] Besley, Timothy (2006), Principled Agents? The Political Economy of Good Government, Oxford University Press.

[7] Besley, Timothy and Anne Case (1995a), "Incumbent Behavior: Vote Seeking, Tax Setting and Yardstick Competition," American Economic Review 85, 25-45.

[8] Besley, Timothy and Anne Case (1995b), "Does Political Accountability Affect Economic Policy Choices? Evidence from Gubernatorial Term Limits," Quarterly Journal of Economics 110, 769-798.

[9] Besley, Timothy and Anne Case (2003), "Political Institutions and Policy Choices: Evidence from the United States," Journal of Economic Literature 41, 7-73.

[10] Besley, Timothy and Andrea Prat (2006), "Handcuffs for the Grabbing Hand? Media Capture and Government Accountability," American Economic Review 96, 720736.

[11] Besley, Timothy and Michael Smart (2007), "Fiscal Restraint and Voter Welfare," Journal of Public Economics 91, 755-773.

[12] Caselli, Francesco and Massimo Morelli (2002), "Bad Politicians," Journal of Public Economics 88, 759-782.

[13] Coate, Stephen and Stephen Morris (1995), "On the Form of Transfers to Special Interests," Journal of Political Economy 103, 1210-1235. 
[14] Dick, Andrew and John R. Lott Jr. (1993), "Reconciling Voters' Behavior with Legislative Term Limits," Journal of Public Economics 50, 1-14.

[15] Fay, Marianne and Mary Morrison (2005), Infrastructure in Latin America $\&$ the Caribbean: Recent Developments and Key Challenges, Report No. 32640-LCR, The World Bank: Washington, DC.

[16] Ferejohn, John (1986), "Incumbent Performance and Electoral Control," Public Choice 50, 5-25.

[17] Fernandez, Raquel and Dani Rodrik (1991), "Resistance to Reform: Status Quo Bias in the Presence of Individual Specific Uncertainty," American Economic Review 81, 1146-55.

[18] Glaeser, Edward (1997), "Self-Imposed Term Limits," Public Choice 93, 389-394.

[19] List, John A., and Daniel Sturm (2006), "How Elections Matter: Theory and Evidence from Environmental Policy," Quarterly Journal of Economics 121, 1249-1281.

[20] Lopez, Edward (2003), "Term Limits: Causes and Consequences," Public Choice $114,1-56$.

[21] Maskin, Eric and Jean Tirole (2004), "The Politician and the Judge: Accountability in Government," American Economic Review 94, 1034-1054.

[22] McMillan, John and Pablo Zoido (2004), "How to Subvert Democracy: Montesinos in Peru," Journal of Economic Perspectives 18, 69-92.

[23] Rogoff, Kenneth (1990), "Equilibrium Political Budget Cycles," American Economic Review 80, 21-36.

[24] Smart, Michael and Daniel Sturm (2006), "Term Limits and Electoral Accountability," typescript.

[25] Tabellini, Guido and Alberto Alesina (1990), "Voting on the Budget Deficit," American Economic Review 80, 37-49. 


\section{Appendix}

We derive the equilibria for the case with a term limit of $T$. We begin by considering the pair of actions $\left(\alpha_{t}^{g}, \alpha_{t}^{b}\right)$, where $\alpha_{t}^{g}$ refers to the action taken by the good incumbent at time $t$ and $\alpha_{t}^{g}$ is defined analogously for the bad type. All of the following seven conditions must be true in equilibrium:

i) In the last two periods the bad types extract rents. In the last period the bad type implements (X). In the next to last period there is no reason to do anything but implement $(\mathrm{X})$, which gives a payoff of at least $\phi y$, and is greater than the best he can do by deviating to $(\mathrm{N})$ or $(\mathrm{L})$, since these provide at most $\delta \phi y$.

ii) If the bad incumbent implements $(X)$ in period $t$, then he implements $(X)$ in all future periods he is in office. Assume that $(\mathrm{X})$ is implemented for the first time in period $t^{\prime}$, so that the incumbent's type becomes known at time $t^{\prime}+1$ at the latest. If a known bad type were to remain in office until period $T-2$, he would then be voted out of office because in periods $T-1$ and $T$ he extracts rents (this follows from i)). Then it is optimal for the bad type to extract rents in period $T-2$. This being so, it is optimal for the voter to remove him from office at the end of period $T-3$. By induction, at the end of $t^{\prime}+1$ the incumbent will be voted out if he is bad, and hence he will choose to extract rents in that period. This establishes that once the bad type implements (X), he will continue to implement it until he is voted out of office.

iii) A bad incumbent can only extract rents in at most two (consecutive) periods. From ii) we know that once rent has been extracted in one period, the bad incumbent will continue to extract rents until he is removed from office. It is then optimal to vote out a bad type as soon as he is recognized. Since (X) is revealed in the next period, then the bad types can extract rents in at most two consecutive periods.

iv) If the bad incumbent's strategy calls for $(X)$ at time $t$, then the good incumbent implements $(L)$ in all future periods he is in office. This is because at that point the incumbent's type, whether good or bad, would be known, and the good incumbent has no reason to implement any policy other than $(\mathrm{L})$.

v) No equilibrium can involve $\alpha_{t}^{g}=N$ and $\alpha_{t}^{b}=L$ or $\alpha_{t}^{g}=L$ and $\alpha_{t}^{b}=N$. These reveal the bad incumbent's type without providing any benefits. In both cases he would deviate to $(\mathrm{X})$.

vi) No equilibrium can involve $\alpha_{t}^{g}=\alpha_{t}^{b}=L$. This would imply that the bad type has not extracted rents yet (otherwise ii) would be violated). By deviating and implementing (X) the bad type receives an expected payoff of $\phi y+\delta \sigma \phi y$, while the most that he can obtain by not deviating is $\delta \sigma(\phi y+\delta \phi y)$, from iii). Since the former is always greater 
than the latter, the bad type would deviate.

vii) No equilibrium can involve $\alpha_{t}^{g}=N$ and $\alpha_{t}^{b}=X$ at any time other than in period 1. Assume that these actions are played in some period $t>1$. Then from iv) it must be that this is the first (X) that the bad type implements. It is also his last, since his type is revealed, and because ii) implies that he will continue implementing (X) until voted out, it is optimal for voters to choose a new incumbent. If this is the case, however, it would have been optimal for him to implement $(\mathrm{X})$ earlier on, contradicting the requirement that this be the first time that $(\mathrm{X})$ is implemented.

From these 7 conditions it follows that any equilibria must have the politicians following one of the following strategies:

a) Paralysis Strategies: Good plays $\alpha_{1}^{g}=N$ and $\alpha_{j}^{g}=L$ for $2<j \leq T$. Bad plays $\alpha_{t}^{b}=X$ for $1 \leq t \leq T$.

We first show that these strategies form part of an equilibrium. In this equilibrium types are perfectly revealed in the first period, and it is optimal for the voter to re-elect the good types and vote the bad types out of office. At $t=1$ the bad types will not deviate if they are sufficiently impatient, as given by $\delta^{2}+\delta<1$. This follows from comparing the payoff from deviation, $\delta \phi y+\delta^{2} \phi y$, with the payoff from no deviation, $\phi y$.

The good incumbent will not deviate at time $t=1$ iff

$$
y+\delta\left[\frac{1-\delta^{T-1}}{1-\delta}\right][(1-\phi) y+\delta \phi y(1+r)]+\delta^{T} K>[(1-\phi) y+\delta \phi y(1+r)]+\delta K
$$

where the left hand side is the value of not deviating when the incumbent can remain at most $T$ terms in office, and the right hand side reflects the fact that the incumbent is voted out of office if he deviates. The continuation value in this equilibrium is given by

$$
K=\frac{\pi\left[y+\delta\left[\frac{1-\delta^{T-1}}{1-\delta}\right][(1-\phi) y+\delta \phi y(1+r)]\right]+(1-\pi)(1-\phi) y}{1-\left[\pi \delta^{T}+(1-\pi) \delta\right]}
$$

where the denominator reflects the fact that different incumbent types remain in office for different lengths of time. Using (8) to solve (7) we obtain the following:

$$
\pi<1-\frac{(1-\delta)}{\left(1-\delta^{T-1}\right)} \frac{\delta(1+r)-1}{\delta^{2}(1+r)}
$$

which is the condition given in the text.

Given these period 1 actions, it is optimal for the bad types to implement (X) in every 
future period (follows from ii)), and so it is optimal for the good types to implement (L) in every future period (follows from iv)).

b) No Paralysis Strategies: Good plays $\alpha_{t}^{g}=L$ for $1 \leq t \leq T$. Bad plays $\alpha_{t}^{b}=X$ for $1 \leq t \leq T$.

There is a no paralysis equilibrium where the optimal re-election rule in periods $t \geq 2$, when the incumbent's type will be known, involves removing the bad types and keeping the good types. In the first period, however, the types remain unknown, and any voting rule is optimal, since the expected payoff from re-electing the incumbent is exactly equal to that of electing a new politician. Since a deviation to $(\mathrm{N})$ could be attributed to either type, it provides no new information. Consequently, the optimal re-election rule following deviation must be the same as when there is no deviation, by the Markov restriction.

The bad incumbent could deviate and play (L). In period 2 it would become clear that no rents were extracted, and he would be re-elected. He will not deviate if $\phi y+\delta \sigma \phi y>$ $\delta \sigma(\phi y+\delta \phi y)$, where the left hand side is the expected payoff from no deviation, while the right hand side is the maximum possible income following deviation. Since this condition always holds, the bad type never deviates in the first period. (Similar reasoning rules out deviations to $(\mathrm{N})$ ). Having implemented (X) in the first period, condition ii) implies that he will not deviate in the future. The good type clearly gains nothing from deviating, since his re-election probability does not change.

c) Pooling Strategies: Let $t^{\prime} \in\{1, \ldots, T-2\}$. In a pooling equilibrium, the good incumbent would play $\alpha_{t}^{g}=N$ for $1 \leq t \leq t^{\prime}$ and $\alpha_{t}^{g}=L$ for $t^{\prime}<t \leq T$. The bad incumbent would play $\alpha_{t}^{b}=N$ for $1 \leq t \leq t^{\prime}$ and $\alpha_{t}^{g}=X$ for $t^{\prime}<t \leq T$.

However, there are no pooling equilibria consisting of these strategies. The reason is that in the first period both types have an incentive to deviate, and so deviations are non-informative. This implies that the equilibrium voting rule must be the same even after a deviation, by the Markov restriction. Since a deviation does not affect the chances of re-election, the good types will deviate to (L) while the bad types will deviate to $(\mathrm{X})$. 